\title{
Diffüz Büyük B Hüicreli Lenfomada Prognostik Skorlama Sistemlerinin Karşılaştırılması
}

\author{
Comparison of Prognostic Scoring Systems in \\ Diffuse Large B Cell Lymphoma
}

\author{
Eda ULUSOY $\mathbb{1}$, Nergiz ERKUT ${ }^{2} \mathbb{D}$, Özlen BEKTAŞ ${ }^{2} \mathbb{D}$, Bircan SÖNMEZ $^{3} \mathbb{D}$, \\ Mehmet SÖNMEZ2苂 \\ ${ }^{1}$ Karadeniz Teknik Üniversitesi Tıp Fakültesi, İç Hastalıkları Anabilim Dalı, Trabzon, Türkiye \\ ${ }^{2}$ Karadeniz Teknik Üniversitesi Tıp Fakültesi, Hematoloji Anabilim Dalı, Trabzon, Türkiye \\ ${ }^{3}$ Karadeniz Teknik Üniversitesi Tıp Fakültesi, Nükleer Tıp Anabilim Dalı, Trabzon, Türkiye
}

\section{öz}

Amaç: Diffüz büyük B hücreli lenfomada (DBBHL) klinik, laboratuvar, biyolojik ve genetik faktörler prognozu etkileyebilir. Yeni faktörlerin eklenmesi ile, yıllar içinde yeni prognostik skorlama sistemleri geliştirilmiştir.

Hastalar ve Yöntem: 2008-2017 yılları arasında Karadeniz Teknik Üniversitesi Tıp Fakültesi Hematoloji bölümünde takip edilen $100 \mathrm{DBBHL}$ hastası retrospektif olarak değerlendirildi.

Bulgular: IPI, R-IPI ve NCCN-IPI risk skorları arttıkça total sağkalım (TS) azalmaktaydı (sırasıyla, $p=$ $0.044, p=0.008, p=0.010$ ). IPI, R-IPI ve NCCN-IPI 3 yıllık TS ve hastalıksız sağkalım (HS) açısından karşılaştııılığında, üç skorlama sistemi de TS'ı öngörüyordu (sırasıyla, $p=0.005, p=0.002, p=$ $0.010)$, ancak HS'ı en iyi öngören NCCN-IPI idi $(p=0.039) .5$ yıllık $\mathrm{HS}^{\prime}$ ı en iyi öngören skorlama sistemleri IPI ve R-IPI idi (sırasıyla, $p=0.047, p=0.004)$.

Sonuç: 3 yıllık HS'ı en iyi NCCN-IPI, 5 yıllık HS'ı en iyi IPI ve R-IPI öngörüyordu.

Anahtar Kelimeler: DBBHL; IPI; R-IPI; NCCN-IPI

\section{ABSTRACT}

Objective: Clinical, laboratory, biological and genetic factors may affect prognosis in diffuse large $B$ cell lymphomas (DLBCL). New prognostic scoring systems have been developed over the years with the addition of new factors.

Patients and Methods: 100 patients with DLBCL during 2008-2017 in Karadeniz Technical University Hematology department were evaluated retrospectively.

Results: Overall survival decreased ( $p=0.044, p=0.008, p=0.010$, respectively) when IPI, R-IPI, and NCCN-IPI risk categories increased. When IPI, R-IPI, and NCCN-IPI were compared for overall survival (OS) and disease free survival (DFS) at 3-year, all were predicting OS ( $p=0.005, p=0.002$, $p=0.010$, respectively), and NCCN-IPI was the best predicting DFS $(p=0.039)$. IPI and R-IPI were better in predicting DFS at 5 -year $(p=0.047, p=0.004$, respectively).

Conclusion: NCCN-IPI was found to be the best predictor for DFS at 3 year and IPI and R-IPI were better in predicting DFS at 5 year.

Key Words: DLBCL; IPI; R-IPI; NCCN-IPI
Makale atıfı: Ulusoy E, Erkut N, Bektaş Ö, Sönmez B, Sönmez M. Diffüz büyük B hücreli lenfomada prognostik skorlama sistemlerinin karşılaştırılması. LLM Dergi 2021;5(2):27-33.

\section{Yazıșma Adresi}

\section{Nergiz ERKUT}

Karadeniz Teknik Üniversitesi, Hematoloji, Trabzon-Türkiye

Geliş: 07.09.2021 - Kabul: 13.10.2021

E-posta: drnusta@hotmail.com 


\section{GíRiş}

Diffüz büyük $B$ hücreli lenfoma (DBBHL) tüm non-Hodgkin lenfomaların (NHL) yaklaşık \%30-40'ını oluşturur (1). İnsidansı yılda 100.000 'de 2.9 olup, yaş artışılyla beraber görülme sıklığı $\operatorname{artar}(2)$.

Birçok klinik, laboratuvar, biyolojik ve genetik faktör NHL'ların prognozunda rol oynar. Ann-Arbor, tutulan lenf nodu veya organ lokalizasyonunu baz alan anatomik bir evreleme sistemi olup tümör biyolojisini göstermede yetersiz olması nedeniyle1993'de Uluslararası Prognostik Indeks (IPI) geliştirildi (3). Rituximab'ın tedaviye eklenmesinden sonra IPI skorunda sadece 2 risk grubunun (düşük/ düşük-orta ve yüksek/orta-yüksek) olduğu öne sürüldü. Bu nedenle Rituksimab uygulanan hastalar için IPI skorlama sistemi revize edildi ve grup sayısı 3 olarak belirlendi. Prognostik faktörler IPI'de kullanılan ile aynıdır (4). Rituksimab kullanan hastalarda IPI skorlama sisteminin düşük ve yüksek grupları tanımlamada yetersiz olması nedeniyle Ulusal Kapsamlı Kanser AğıIIPI (NCCN-IPI) skorlama sistemi geliştirildi. NCCN-IPI'de IPI'den farklı olarak yaş aralığı ve LDH düzeyleri derecelendirilmiş ve ekstranodal tutulum sayısı yerine spesifik ekstranodal tutulum ilave edildi. Çalışmalar, prognozu öngörmede NCCN-IPI'nin IPI ve R-IPI'den daha üstün olduğunu göstermektedir (5).

Bu çalışmada DBBHL'da farklı prognostik evreleme sistemlerinin karşılaştıııımasını amaçladık.

\section{HASTALAR ve YÖNTEM}

Karadeniz Teknik Üniversitesi Tıp Fakültesi Etik Kurul'undan onay alındıktan sonra 2008-2017 yılları arasında takip edilmiş $100 \mathrm{DBBHL}$ hastası bu retrospektif çalışmaya dahil edildi. Her hasta, tanıdaki LDH düzeyi, yaş, ekstranodal tutulum, hastalık evresi ve ECOG skorlarına göre, IPI, R-IPI ve NCCN-IPI prognostik skorlama sistemlerine göre sınıflandıııldı. Her üç skorlama sistemi; yaş, evre, serum LDH düzeyi, ECOG performans skoru ve ektranodal bölge tutulumu kriterleri ile belirlendi. Tedavi protokolleri, remisyon ve relaps durumları, son takip tarihi ve ölüm tarihleri kaydedildi. Hastalık yanıtı Lugano kriterlerine (6) göre değerlendirildi ve tedavi yanıtı tam yanıt (TY), kısmı yanıt $(\mathrm{KY})$, stabil hastalık $(\mathrm{SH})$ ve progresif hastalık $(\mathrm{PH})$ olarak belirlendi. Tanı tarihinden ölüm veya son kontrol tarihine kadar geçen sure genel sağkalım (GS), TY'tan relaps veya son kontrol tarihine kadar geçen süre hastalıksız sağkalım (HS) olarak tanımlandı. Her ikisi de ay olarak hesaplandı.

\section{İstatistiksel Metod}

Veriler SPSS Windows 23.0 software ile analiz edildi. Sürekli değişkenler mean \pm standard deviation veya median; kategorik değişkenler sayı ve yüzde olarak belirtildi. Bağımsız gruplardaki kategorik değişkenler arasındaki de- ğerlendirmeler Ki-kare testi ile değerlendirildi. IPI, R-IPI ve NCCN-IPI için toplam sağkalım, hastalıksız sağkalım, 1, 3 ve 5 yıllık sağkalım oranları ve \%95 güven aralığı Kaplan-Meier sağkalım analizi ile hesaplandı. IPI, R-IPI ve NCCN-IPI'nin GS ve HS için öngörücülüğü Multivariate Cox' proportional hazard regresyon analizi ile karşılaştırıldı. Her bir değişken için hazard oranı ve $\% 95$ güven aralığı hesaplandı. $\mathrm{P}<0.05$ istatistiksel olarak anlamlı kabul edildi.

\section{BULGULAR}

\section{Hasta Özellikleri}

Hastaların 59'u (59\%) erkek, 41'i (41\%) kadındı. Ortalama yaş $56.8 \pm 15.8$ saptandı.

Ann-Arbor sınıflamasına göre; 13 hasta (\%13) evre I, 32 (\%32) evre II, 20 (\%20) evre III ve 35 (\%35) evre IV idi. 43 (\%43) hastada ekstranodal tutulum, 3 hastada (\%3) bulky hastalık ve 67 (\%67) hastada B semptomları mevcuttu. Tanıda ECOG performans skoru 88 (\%88) hastada 0-1, 12 hastada (\%12) 2-4 idi. Tanı anında hastaların IPI skoru 43 (\%43) hastada düşük, 35 (\%35) hastada düşük-orta, 17 (\%17) hastada yüksek-orta, $5(\% 5)$ hastada yüksek riskli idi. R-IPI skoru 23 (\%23) hastada çok iyi, 55 (\%55) hastada iyi, 22 (\%22) hastada kötü idi. NCCN-IPI skoru 17 (\%17) hastada düşük, 46 (\%46) hastada düşük-orta, 33 (\%33) hastada yüksek-orta, $4(\%)$ hastada yüksek riskli idi.

Illk sıra tedavi olarak hastaların 83'üne (\%83) R-CHOP (rituksimab, siklofosfamid, doksorubisin, vinkristin, ve prednizon) ve 17 'sine (\%17) R-CHOP benzeri (R-mini CHOP, R-COEP) tedavileri uygulandı. 12 hasta otolog kök hücre tedavisi ile tedavi edildi. Hastalar ortalama 36.5 ay (1-130) takip edildi.

Illk sıra tedavi sonrası \%86 TY, \%8 KY elde edildi. Dört hasta (\%4) tedaviye dirençli idi ve 2 hasta (\%2) tedavi yanıtı değerlendirilemeden öldü. Takip süresi boyunca 32 hastada (\%32) relaps gelişti.

GS 36.5 ay $(I Q R=34)$ ve HS 27.5 ay $(I Q R=34.75)$ bulundu. IPI, R-IPI ve NCCN-IPI'de, prognostik skorlar arttıkça GS'nin azaldığı gözlendi (sırasıyla, $p=0.044, p=0.008, p=$ 0.010). Hiçbir skorlama sistemi genel HS'ı öngörmede başarılı değildi (Tablo 1, Şekil 1a, 1b, 1c, 2a, 2b, 2c).

Bir yıllık sağkalım analizinde IPI, R-IPI ve NCCN-IPI skorlama sistemleri arasında GS ve HS'yi öngörmede anlamlı fark saptanmadı. Üç yıllık sağkalım analizine erişen 75 ve 5 yıllık sağkalım analizine erişen 44 hasta vardı. IPI, R-IPI ve NCCN-IPI skorlama sistemleri 3 yıllık GS ve HS için karşılaştırıldığında, GS'yi her üçü de (sırasıyla, $p=0.005, p=0.002$, $p=0.010)$; HS'yi en iyi NCCN-IPI öngörüyordu $(p=0.039) .5$ yıllık analizde IPI ve R-IPI en iyi HS'yi (sırasıyla, $p=0.047, p=$ 0.004) öngörüyordu. IPI , R-IPI ve NCCN-IPI'ye göre 1, 3 ve 5 yıllık GS ve HS, Tablo 2 ve 3'te sunulmuştur. 
Tablo 1. IPI, R-IPI ve NCCN-IPI'ye göre GS ve HS

\begin{tabular}{|c|c|c|c|c|}
\hline Değişkenler & GS (ay) (\%95 Cl) & $\mathbf{p}$ & HS (ay) (\%95 CI) & $\mathbf{p}$ \\
\hline \multicolumn{5}{|l|}{ IPI } \\
\hline Düşük & $94.44(84.44-104.43)$ & \multirow{4}{*}{0.046} & $65.10(52.85-77.35)$ & \multirow{4}{*}{0.400} \\
\hline Düşük - Orta & $52.88(43.52-62.23)$ & & $33.41(25.40-41.42)$ & \\
\hline Orta - Yüksek & $76.34(46.44-106.24)$ & & $85.06(51.76-118.36)$ & \\
\hline Yüksek & $42.20(86.82-108.66)$ & & $40.00(17.59-62.40)$ & \\
\hline \multicolumn{5}{|l|}{ R-IPI } \\
\hline Çok iyi & 86.54 (79.93-93.16) & \multirow{3}{*}{0.008} & $72.58(59.80-85.36)$ & \multirow{3}{*}{0.056} \\
\hline İyi & 78.47 (65.77-91.18) & & $45.20(30.68-59.71)$ & \\
\hline Kötü & 75.52 (86.82-108.66) & & 74.46 (42.73-106.19) & \\
\hline \multicolumn{5}{|l|}{ NCCN-IPI } \\
\hline Düşük & 85.25 (76.23-94.26) & \multirow{4}{*}{0.010} & $72.30(57.27-87.32)$ & \multirow{4}{*}{0.130} \\
\hline Düşük - Orta & 87.15 (75.04-99.26) & & $56.82(42.58-71.05)$ & \\
\hline Yüksek - Orta & $78.73(57.23-100.23)$ & & $69.21(45.28-93.14)$ & \\
\hline Yüksek & $33.00(3.68-62.32)$ & & $29.00(0-58.40)$ & \\
\hline
\end{tabular}

\section{TARTIŞMA ve SONUÇ}

IPI 20 yıldan uzun süredir kullanılan bir prognostic skorlama sistemidir (5). Rituksimab öncesi dönemde geliştirilmesi nedeniyle günümüzde hastalık prognozunu yansıtmaması ana eleştiri noktasıdır (7). Ek olarak, yalnızca 2 risk grubunu (düşük/düşük-orta ve yüksek/orta-yüksek) tanımlar. R-IPI klinik sonuçları öngörmede daha etkilidir ve 3 farklı prognostik grubu (çok iyi, iyi ve kötü) tanımlar (4). Her iki skorlama sistemi, rituksimab döneminde de hala günceldir fakat düşük öngörücülüğe sahiptirler çünkü 5 yıllık GS, kötü risk grubunda bile hala \%50'den düşük değildir $(5,7)$.

Prognostik skorlama sistemlerini karşılaştıran birkaç çalışma mevcuttur. Yang ve arkadaşları validasyon çalışmalarında IPI, R-IPI, ve NCCN-IPI'yi karşılaştırdılar. Bu çalışmada, yüksek riskli olan grupta 3 yıllık GS ve progresyonsuz sağkalımın NCCN-IPI'de, IPI ve R-IPI'ye göre daha düşük olduğunu gösterdiler. Ayrıca yüksek risk grubunda sağkalım, orta-yüksek gruba göre anlamlı şekilde farklı bulundu (7). Bizim çalışmamızda, IPI, R-IPI ve NCCN-IPI GS'ı öngörüyordu (sırasılya, $p=0.005, p=0.002, p=0.010$ ) ve 3 yıllık analizde, R-IPI ve NCCN-IPI risk gruplarını iyi ayırdediyordu (sırasıyla, $\% 94.1, \% 74.4, \% 40.0$ ve $\% 92.3, \% 81.8, \% 53.8, \% 33.3$ ). Üç yıllık analizde HS'ı en iyi öngören NCCN-IPI $(p=0.039)$ idi.

Zhou ve arkadaşlarının IPI ve NCCN-IPI'yi kıyasladıkları çalışmaşlarında, 5 yıllık GS'da NCCN-IPI'nin düşük ve yüksek gruplarını daha iyi ayırt ettiğini gösterdiler (5). Ruppert ve arkadaşları 5 yıllık analizde, düşük ve yüksek risk grupları arasında GS'ı en iyi öngörenin NCCN-IPI olduğunu gösterdiler (8). Bizim çalışmamızda, 5 yıllık GS analizinde NCCN-IPI dahil hiçbir skorlama sistemi risk gruplarını ayırt etmede iyi bulunmadı (5 yıllık GS, IPI için \%62.5, \%23.1, \%36.4 ve \%50; R-IPI için \%85.7, \%31.8 ve \%40.0; NCCN-IPI için \%83.3, \%41.8, \%31.6 ve \%33.3). Nakaya ve arkadaşları bizim çalışmamızla benzer şekilde, NCCN-IPI'nin yüksek riskli DBBHL'li hastaları ayırt etmede iyi olmadığını tespit etmişler ve yaş uyumlu IPI'nin Japon hastalarda daha iyi bir skorlama sistemi olduğunu iddia etmişlerdir (9). Bizim çalışmamızda 5 yıllık analizde HS'ı predikte etmede en iyi skorlama sistemleri IPI ve R-IPI idi (sırasıyla, $p=0.047, p=$ 0.004). NCCN-IPI'de yüksek riskli grupta 5 yıllık HS'a ulaşan hasta mevcut değildi. Bu, yüksek riskli grupta 5 yıllık HS'ı göstermede NCCN-IPI'nin daha anlamlı olduğunu düşündürebilir ancak bu sonuç istatistiksel anlamlı bulunmadı. İstatistiksel anlamlı sonuç elde edilememesinin nedeni, 5 yıllık HS analizine ulaşabilen hasta sayısının sadece 44 olması olabilir. Hasta sayısındaki bu kısıtılıı çalışmamızın handikapı idi. Vaka sayılarının arttırıması daha farklı sonuçların elde edilmesini sağlayabilir.

Sonuç olarak, 3 yıllık analizde IPI, R-IPI ve NCCN-IPI GS'ı öngörüyorken, HS'ı en iyi NCCN-IPI öngörüyordu. 5 yıllık analizde HS'ı en iyi IPI ve R-IPI öngörüyordu.

\section{ETIK KURUL ONAYI}

Çalışma için Karadeniz Teknik Üniversitesi Tıp Fakültesi Bilimsel Araştırmalar Etik Kurulu'ndan onay alındı. (Tarih: 02.03.2018, Karar no: 2018/40).

\section{ÇIKAR ÇATIŞMASI}

Yazarların çıkar çatışması bulunmamaktadır. 


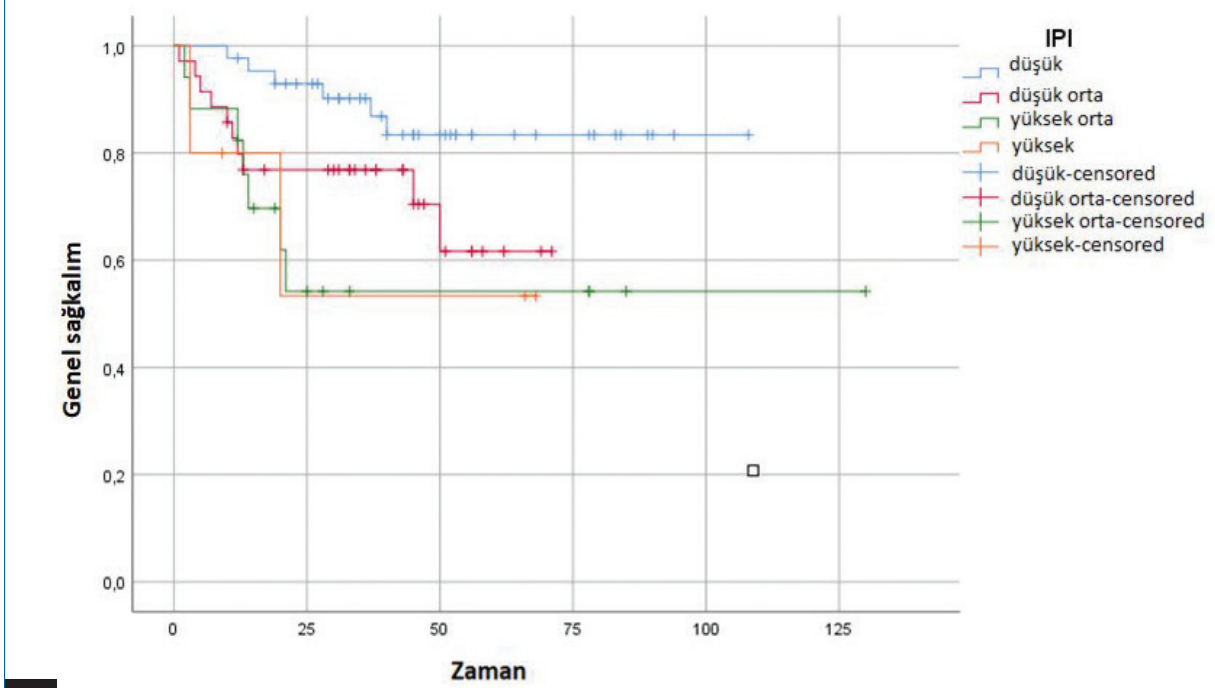

A

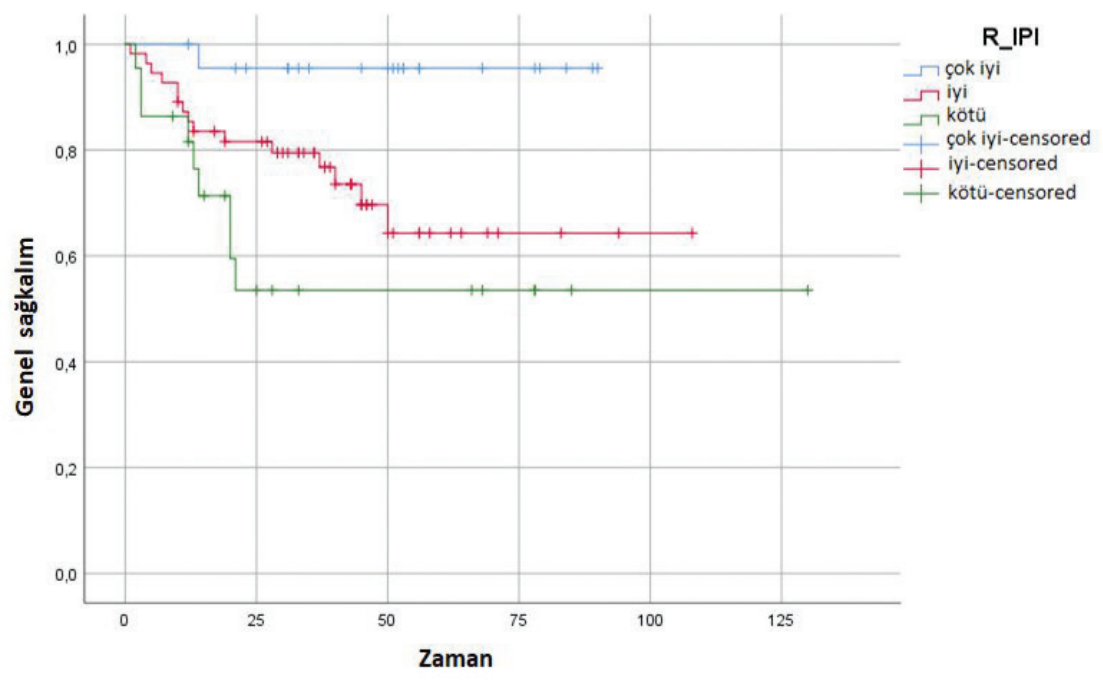

B

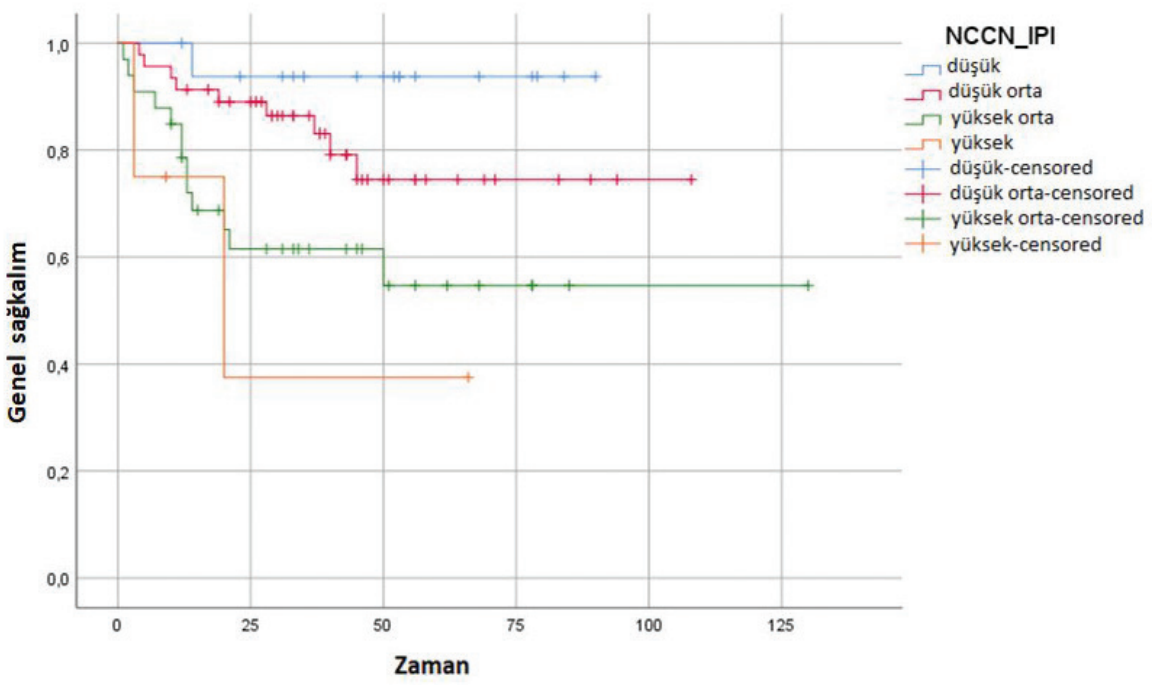

Şekil 1. IPI, R-IPI ve NCCN-IPI risk gruplarına göre genel sağkalım. 


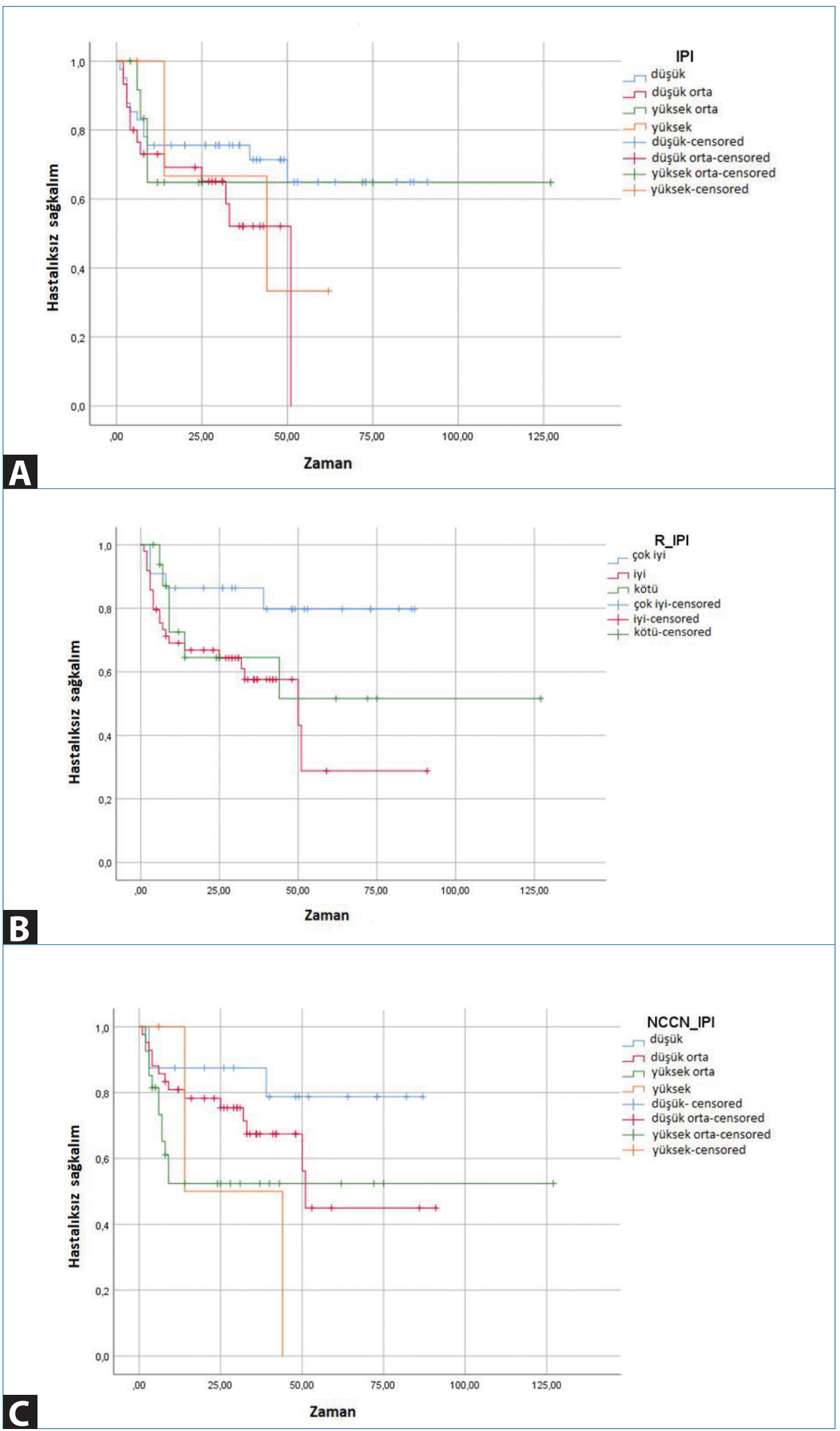

Şekil 2. IPI, R-IPI ve NCCN-IPI risk gruplarına göre hastalıksız sağkalım. 


\begin{tabular}{|c|c|c|c|c|c|c|}
\hline \multirow[b]{2}{*}{ Değişkenler } & \multicolumn{6}{|c|}{ Genel sağkalım oranı (\%) } \\
\hline & 1 Yıl & p & 3 YIl & p & 5 YIl & $\mathbf{p}$ \\
\hline \multicolumn{7}{|l|}{ IPI } \\
\hline Düşük & 97.7 & \multirow{4}{*}{0.112} & 87.9 & \multirow{4}{*}{0.005} & 62.5 & \multirow{4}{*}{0.100} \\
\hline Düşük - Orta & 82.4 & & 70.4 & & 23.1 & \\
\hline Orta - Yüksek & 88.2 & & 36.4 & & 36.4 & \\
\hline Yüksek & 75.0 & & 50.0 & & 50 & \\
\hline \multicolumn{7}{|l|}{ R-IPI } \\
\hline Çok iyi & 100 & \multirow{3}{*}{0.189} & 94.1 & \multirow{3}{*}{0.002} & 85.7 & \multirow{3}{*}{0.098} \\
\hline İyi & 87 & & 74.4 & & 31.8 & \\
\hline Kötü & 85.7 & & 40 & & 40.0 & \\
\hline \multicolumn{7}{|l|}{ NCCN-IPI } \\
\hline Düşük & 100 & \multirow{5}{*}{0.154} & 92.3 & \multirow{5}{*}{0.010} & 83.3 & \multirow{5}{*}{0.202} \\
\hline Düşük - Orta & 91.3 & & 81.8 & & 43.8 & \\
\hline Orta - Yüksek & 84.4 & & 53.8 & & 31.6 & \\
\hline Yüksek & 66.7 & & 33.3 & & 33.3 & \\
\hline Genel & 89.8 & & 72.0 & & 43.2 & \\
\hline
\end{tabular}

\section{Tablo 3. 1, 3 ve 5. yıllarda HS}

\begin{tabular}{|c|c|c|c|c|c|c|}
\hline \multirow[b]{2}{*}{ Değişkenler } & \multicolumn{6}{|c|}{ Hastalıksız sağkalım oranları (\%) } \\
\hline & 1 Yıl & $\mathbf{p}$ & 3 YII & $\mathbf{p}$ & $5 \mathrm{YII}$ & $\mathbf{p}$ \\
\hline \multicolumn{7}{|l|}{ IPI } \\
\hline Düşük & 85.4 & \multirow{4}{*}{0.781} & 70.6 & \multirow{4}{*}{0.351} & 40.0 & \multirow{4}{*}{0.047} \\
\hline Düşük - Orta & 79.3 & & 47.6 & & 0 & \\
\hline Orta - Yüksek & 84.6 & & 42.9 & & 42.9 & \\
\hline Yüksek & 100 & & 66.7 & & 33.3 & \\
\hline \multicolumn{7}{|l|}{ R-IPI } \\
\hline Çok iyi & 90.9 & \multirow{3}{*}{0.387} & 82.4 & \multirow{3}{*}{0.131} & 60.0 & \multirow{3}{*}{0.004} \\
\hline İyi & 79.2 & & 52.6 & & 8.7 & \\
\hline Kötü & 87.5 & & 50.0 & & 40.0 & \\
\hline \multicolumn{7}{|l|}{ NCCN-IPI } \\
\hline Düşük & 87.5 & \multirow{5}{*}{0.347} & 84.6 & \multirow{5}{*}{0.039} & 62.5 & \multirow{5}{*}{0.263} \\
\hline Düşük - Orta & 88.1 & & 64.5 & & 17.6 & \\
\hline Orta - Yüksek & 73.1 & & 36.8 & & 25.0 & \\
\hline Yüksek & 100 & & 50.0 & & 0 & \\
\hline Genel & 89.8 & & 72.0 & & 43.2 & \\
\hline
\end{tabular}

\section{MALI AÇIKLAMA}

Çalışma için doğrudan veya dolaylı mali destek alınmadı. Çalışma ile ilgili herhangi bir firma veya kişi ile ilgili ticari bağlantı yoktur.

\section{YAZAR KATKISI}

Literatür taranması: EU; Vakaların takip ve tedavi aşamaları: EU, BS, MS; Verilerin toplanması: EU, BS, MS; Makalenin yazımı: EU; Onaylama: Tüm yazarlar. 


\section{KAYNAKLAR}

1. Armitage JO, Gascoyne RD, Lunning MA, Cavalli F. Non-Hodgkin lymphoma. The Lancet 2017;390(10091):298-310.

2. Morgan G, Vornanen M, Puitinen J, Naukkarinen A, Brincker $H_{\text {, }}$ Olsen J, et al. Changing trends in the incidence of non-Hodgkin's lymphoma in Europe. Biomed Study Group. Ann Oncol 1997;8(Suppl 2):49-54.

3. The International Non-Hodgkin's Lymphoma Prognostic Factors Project. A predictive model for aggressive non-Hodgkin's lymphoma. N Engl J Med 1993;329:987-9.

4. Sehn LH, Berry B, Chhanabhai M, Fitgerald C, Gill K, Hoskins $P$, et al. The revised International Prognostic Index (R-IPI) is a better predictor of outcome than the standard IPI for patients with diffuse large B-cell lymphoma treated with R-CHOP. Blood 2007;109(5):1857-61.

5. Zhou Z, Sehn LH, Rademaker AW, Gordon LI, Lacasce AS, Crosby-Thompson A, et al. An enhanced International Prognostic Index (NCCN-IPI) for patients with diffuse large B-cell lymphoma treated in the rituximab era. Blood 2014;123(6):837-42.
6. Cheson BD, Fisher RI, Barrington SF, Cavalli F, Schwartz LH, Zucca $E$, et al. Recommendations for initial evaluation, staging, and response assessment of Hodgkin and non-Hodgkin lymphoma: the Lugano classification. J Clin Oncol 2014;32:3059-68.

7. Yang Y, Wang L, Ma Y, Han T, Huang M. The enhanced international prognostic index for diffuse large B-cell lymphoma. Am J Med Sci 2017;353:459-65.

8. Ruppert AS, Dixon JG, Salles GA, Wall A, Cunningham D, Poeschel $\mathrm{V}$, et al. International prognostic indices in diffuse large B-cell Iymphoma (DLBCL): a comparison of IPI, R-IPI and NCCN-IPI. Blood 2020 Jun 4;135(23):2041-8.

9. Nakaya A, Fujita S, Satake A, Nakanishi T, Azuma Y, Tsubokura Y, et al. Enhanced international prognostic index in Japanese patients with diffuse large B-cell lymphoma. Leuk Res Rep 2016;6:24-6. 